Sección monográfica/ Monographic section

\title{
Las utopías reales de Erik Olin Wright: ¿una reconstrucción científica del socialismo utópico?
}

\author{
The real utopias of Erik Olin Wright: A scientific reconstruction of \\ the utopian socialism?
}

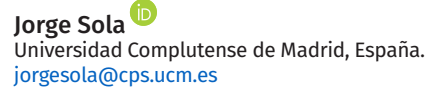

Recibido / Received: 26/06/2020 Aceptado / Accepted: 02/12/2020

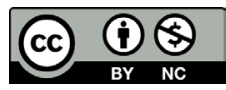

\section{RESUMEN}

El conjunto de la obra de Erik O. Wright puede concebirse como un esfuerzo por reconstruir el marxismo en dos direcciones: el análisis de clase y la formulación de alternativas al capitalismo, a las que llamó "utopías reales". Este artículo se propone ofrecer un balance crítico de este segundo programa de investigación. Para ello, tras presentar el proyecto de las utopías reales y enmarcarlo en la agenda de una "ciencia social emancipadora", se examinan tanto el marco teórico-conceptual que sirve de base al diseño institucional de estas propuestas utópico-realistas como la defensa de Wright de una estrategia gradualista de erosión del capitalismo. Ambos planos -el institucional y el estratégico- se caracterizan por un pluralismo que busca liberar a la imaginación política de ciertos marcos mentales en los que suele quedar confinada, lo que hace de este intento por reconciliar el espíritu utópico con la investigación científica un programa abierto a desarrollos futuros.

Palabras clave: capitalismo, utopías reales, ciencia social, marxismo, Erik Wright.

\begin{abstract}
The work of Erik O. Wright can be conceived as an attempt for reconstructing Marxism in two directions: class analysis and the discussion of alternatives to capitalism called "real utopias". This article aims to offer a critical assessment of this second research program. First, the real utopias project is presented within the broaderagenda ofan "emancipatory social science". Then, both the theoretical framework that serves as the basis for the institutional design of these proposals and the gradualist strategy for eroding capitalism are critically analyzed. Both -institutional and strategic- levels are characterized by a pluralism that seeks to liberate the political imagination from certain mental frameworks in which it is often confined, which makes this attempt to reconcile the utopian spirit with scientific enquiry a promising research program for future developments.
\end{abstract}

Keywords: capitalism, real utopias, social science, Marxism, Erik Wright. 


\section{INTRODUCCIÓN}

El conjunto de la obra de Erik Olin Wright puede entenderse como una apuesta por la reconstrucción del marxismo desde la sociología, por más que el interés de su trabajo desborde ampliamente los confines de esta tradición político-intelectual. Si bien es cierto que, a estas alturas de la historia, la etiqueta puede resultar imprecisa o equívoca, Wright (2008) identificaba la tradición marxista con estos tres principios: el compromiso con un ideal emancipador democrático e igualitario; el estudio y la crítica del capitalismo basados en el análisis de clase; y la búsqueda de una alternativa institucionalmente viable a ese sistema que encarnase tal ideal normativo, y a la que tradicionalmente se había llamado "socialismo".

Animado por el compromiso político con ese ideal igualitario-democrático, Wright produjo el grueso de su trabajo intelectual en estas dos direcciones: la renovación del análisis de clase (Wright, 1994, 1997, 2015) y la búsqueda de alternativas al capitalismo, a las que llamó "utopías reales" (Wright, 2014, 2019). En este sentido, resulta llamativa la coherencia retrospectiva que adquiere su obra: con la excepción de sus incursiones puntuales en la filosofía de la ciencia (Wright, Levine y Sober, 1992) y la teoría del Estado (Wright, 1983), su producción intelectual giró en torno a la clase y las utopías en la estela de la tradición marxista.

Esta coherencia no debe ocultar una cierta discontinuidad entre sus dos grandes programas de investigación. Su alter ego Michael Burawoy (2020) ha señalado la falta de polinización cruzada entre los "dos marxismos" -el científico y el crítico- de Wright: "análisis de clase sin utopía, utopías sin análisis de clase" (p. 69). Pero esa distinción puede resultar engañosa, pues si bien la clase retrocede a un segundo plano en su trabajo en torno a las utopías reales, su énfasis en el conocimiento científico de la realidad social sigue desempeñando un papel muy relevante.

Este artículo se propone examinar las ideas centrales y ofrecer un balance crítico de esta segunda etapa de la obra de Wright: la discusión de las utopías reales en el marco de una reformulación teórico-política del socialismo. Desde los años noventa hasta su reciente fallecimiento, han visto la luz siete volúmenes colectivos (más otro en camino) en torno a sendas propuestas "utópico-realistas", así como un ambicioso libro que ofrecía el marco general del proyecto y otro póstumo que presentaba de un modo más directo (y revisado) sus principales ideas. El objetivo del artículo es destacar las aportaciones más interesantes y señalar las limitaciones más importantes de esta agenda investigadora, que puede interpretarse como un intento de reconciliar el espíritu utópico con la investigación científica.

El artículo está dividido en cinco apartados. El primero ofrece una visión general que conecta el proyecto de las utopías reales con el contexto histórico que la rodeó y la crisis del marxismo. El segundo examina con más detalle el análisis de las utopías reales, como una de las tareas de lo que denomina "ciencia social emancipadora". El tercero analiza el marco político-teórico en el que se insertaban las utopías reales, subrayando el pluralismo institucional que subyacía a la visión del socialismo de Wright. El cuarto aborda su apuesta por el pluralismo estratégico dentro de una vía gradualista para erosionar el capitalismo. Por último, se ofrecen unas reflexiones finales a modo de conclusión'.

\footnotetext{
1 Uno de los rasgos que caracterizaron a Wright fue la soltura con la que se movió entre dos públicos relativamente distintos: la sociología académica y la política socialista. Por esa razón, este artículo está escrito con esos dos tipos de lectores en mente (y con un tercero, claro está, movido por ambas inquietudes).
} 


\section{LA IMAGINACIÓN UTÓPICA DESPUÉS DEL FIN DE LA HISTORIA}

El Real Utopias Project echó a andar a principios de los años noventa y responde al contexto ideológico de aquella época. El desplome de la Unión Soviética agravó la crisis larvada que vivían los movimientos políticos anticapitalistas y propició la difusión del discurso del "fin de la historia". Wright fecha en 1992, el año en que se publicó el influyente libro de Francis Fukuyama, su vuelta al tema de las utopías, sobre las que ya había trabajado veintitantos años antes, en el seminario religioso al que se apuntó para librarse del alistamiento militar.

Pero junto a las ruinas del muro de Berlín se amontonaban también los escombros del "materialismo histórico" entendido, en un sentido restrictivo, como una teoría de la historia que había acaparado buena parte de los debates del September Group de marxistas analíticos del que formaba parte (Wright, 1993). El propio intercambio intelectual con este grupo le condujo a interesarse por cuestiones normativas y por su plasmación práctica, bajo la influencia, sobre todo, de Gerald Cohen, Philippe van Parijs y John Roemer.

La motivación y el propósito del proyecto eran claros: en una época de escepticismo y cinismo ante los proyectos emancipadores de cambio social, la discusión de alternativas radicales a las instituciones existentes era una tarea intelectual primordial; el objetivo no debían ser formulaciones abstractas y grandilocuentes ni pequeños cambios en las políticas públicas, sino "propuestas específicas para el rediseño fundamental de instituciones sociales básicas" (Wright, 1995, p. xii). Frente a la máxima neoliberal de que "no había alternativa", se trataba de mostrar que "otro mundo era posible", por usar un lema que se difundiría pocos años más tarde.

Wright no fue el único marxista que volvió su mirada hacia las utopías. La caída del bloque soviético, el descrédito de un cierto marxismo y la sensación de impotencia política produjeron un renovado interés por este tema entre muchos otros teóricos, como Frederic Jameson (2007), David Harvey (2005) o, en nuestro país, Francisco Fernández Buey (2007); pero lo específico de Wright fue que su objetivo no era escribir acerca de las utopías, sino... diseñarlas. Se trataba -en palabras de Göran Therborn (2007, p. 77)- de "una iniciativa colectiva a gran escala de ingeniería social radical", por más que, como veremos más adelante, la ambición de las propuestas utópico-realistas fuera bastante desigual.

Esta reivindicación de la utopía contrastaba con el tradicional desdén que había recibido desde la tradición marxista. Según la exposición clásica de Engels, el progreso teórico-político del movimiento obrero había consistido precisamente en pasar del socialismo utópico al socialismo científico. Si el primero "pretendía sacarse de la cabeza la solución a los problemas sociales" pensando que "bastaba con descubrir [el socialismo] para que su virtud conquistara el mundo", el segundo partía del análisis de la realidad existente: "su misión ya no era elaborar un sistema lo más perfecto posible de sociedad, sino investigar el proceso histórico-económico" que subyacía a la división y el conflicto de clase (Engels, 1968, pp. 62-73). Pero en este sentido, la recuperación de la utopía por parte de Wright no consistía en una vuelta atrás, pues también se proponía buscar en la propia realidad capitalista "los medios necesarios para poner término a los males descubiertos" (Engels, 1968, p. 75)².

En cierto modo, la apuesta de Wright puede interpretarse como una reconciliación de las dimensiones utópica y científica del socialismo: su reflexión está firmemente anclada en el análisis sistemático del capitalismo, pero lo que busca no son tanto las semillas de

\footnotetext{
2 De todos modos, es probable que el retrato que hace Engels de los socialistas utópicos, y la imagen que luego quedó de ellos, pasen injustamente por alto la atención que muchos de esos pensadores prestaron al conocimiento científico como base para el progreso político (ver, especialmente, Jones, 1984).
} 
su propia destrucción, sino más bien aquéllas sobre las que puedan florecer alternativas institucionales igualitarias y democráticas. Una vez que la visión teleológica del marxismo dominante y su confianza en que navegaba a favor de la corriente de la historia se habían desplomado, lo importante no era tanto analizar los procesos y mecanismos que aseguraban la inviabilidad del capitalismo sino aquellos que permitían imaginar la viabilidad del socialismo.

En ese sentido, la burla de Marx (1975) a la idea de "construir recetas de cocina para los bodegones del porvenir" (p. 17) o la opinión de Engels (1968) de que "cuanto más detallados y minuciosos fueran [los experimentos utópicos], más tenían que degenerar en puras fantasías" (p. 57) se habían convertido, desde hacía tiempo, en un lastre para el desarrollo de la imaginación política. En su historia del socialismo, Donald Sassoon (2001) lamenta que durante el periodo de la II Internacional "el diseño de la sociedad posrevolucionaria apenas se discutió", y comenta con sorna que "los socialistas no parecían muy interesados en el socialismo" (p. 45). En referencia al periodo de entreguerras señala que "prácticamente en todos los casos los partidos socialistas siempre parecían entrar en los gobiernos sin saber realmente qué hacer (...) como si la historia les hubiera engañado cediéndoles [el poder] prematuramente, cuando todavía andaban faltos de ideas para manejarlo" (Sassoon, 2001, p. 73).

Todo ello contribuyó a que se afianzara la creencia de que hasta que no cambiara todo apenas se podía hacer nada, lo que condujo a la coexistencia, un tanto esquizofrénica, de una verborrea revolucionaria y un pragmatismo resignado ${ }^{3}$. La experiencia soviética no mejoró las cosas. Como escribió Cohen (2001): “La historia del fracaso socialista muestra que los socialistas sí que necesitan escribir recetas, y no sólo para saber lo que hacer con el poder, sino también para atraer a las masas, que creen, de modo muy razonable, que más vale lo malo conocido. A menos que escribamos recetas para futuras cocinas, no hay razón para pensar que tendremos la comida que nos gusta" (p. 49).

El modus operandi de Wright para elaborar ese recetario era el siguiente ${ }^{4}$. Organizaba encuentros periódicos, desde el Havens Center de Madison ${ }^{5}$, que giraban en torno a la discusión de una propuesta central elaborada por una o varias personas. Cada encuentro reunía a un grupo de investigadores de diferentes disciplinas que antes habían preparado una aportación en respuesta a dicha propuesta que abordaba alguno de sus aspectos. En el encuentro se debatían uno a uno estos textos, y todos ellos -tanto el principal como el resto y una réplica final- aparecían luego en un volumen editado por el propio Wright.

Lo esencial de esta forma de trabajar era que involucraba a diferentes investigadores en una empresa colectiva basada en el debate público y el intercambio crítico de ideas. El resultado son siete gruesos volúmenes (y uno más en camino sobre la democratización de las finanzas) que cubren, cada uno de ellos, un debate exhaustivo sobre los diferentes aspectos normativos y prácticos de diferentes "utopías reales" (Ackerman, Alstott y Parijs, 2006; Bowles y Gintis, 1998; Cohen y Rogers, 1995; Gastil y Wright, 2019; Gornick y Meyers,

3 Esto implicaba en ocasiones aplicar políticas económicas directamente ortodoxas (ver, por ejemplo, el caso de Hilferding como ministro de Finanzas alemán, en Mudge, 2018).

4 Ese modus operandi resume a la perfección su forma de concebir y organizar el trabajo intelectual, que también trasladaba a la docencia: en un curso de doctorado organizaba la discusión de modo que cada estudiante tenía que enviar una reflexión breve sobre las lecturas y, antes de la sesión, debía leer las de los demás y los comentarios que Erik había hecho a cada una de ellas. En ocasiones, invitaba a participar por videollamada al autor del libro sobre el que giraba una sesión, por más que fuera abiertamente contrario a sus posiciones (como lo era, por ejemplo, el autor de The classless society, Paul Kignston). Y al final del semestre organizaba un retiro en un albergue para debatir los trabajos de los estudiantes. Como recuerda Gay Seidman (2020) que solía decir una antigua compañera suya, Erik tenía la personalidad de un director de un campamento de verano.

5 El Havens Center for Social Justice fue creado por Wright en los años ochenta para animar la reflexión crítica por medio de charlas y seminarios de profesores visitantes. Su historia es menos conocida: la Universidad de Berkeley intentó ficharle y la Universidad de Madison reaccionó con una cuantiosa contraoferta, pero Wright respondió que no quería hablar de dinero y que lo único que pedía era que le dieran fondos para financiar este centro (Middleton, 2017), que ahora ha sido renombrado como Havens-Wright Center. 
2009; Roemer, 1996). Estos trabajos son un ejemplo del uso refinado de la mejor ciencia social para el debate político, pero su limitación práctica era que su extensión y complejidad los hacían poco accesibles para un lector no académico. Aunque eso pueda parecer secundario, no lo es tanto si se considera que el objetivo último del proyecto no era sólo analizar el mundo sino transformarlo ( $y$, en todo caso, se trata de un obstáculo más relacionado con la transferencia social del conocimiento que con el agit-prop revolucionario).

Dicha limitación quizás pueda entenderse mejor a la luz del contexto político del cambio de siglo: en una época de reflujo político, el público interesado en estas propuestas se había reducido y muchos intelectuales críticos se habían tomado al pie de la letra el consejo de Jon Elster (1991): “iVolvamos al Museo Británico!” (p. 18). Cuando Wright escribió Construyendo utopías reales lo hizo "pensando en un público más amplio y relativamente popular" (Wright, 2010, p. 14), aunque el resultado en ese aspecto fuera -como él mismo admitía- un tanto desigual 6 . Fueron las giras por el mundo con conferencias y seminarios en torno a este libro y el consecuente contacto con audiencias menos académicas, así como la irrupción de una nueva generación de movimientos y activistas durante la última década -en cuyos medios, como Jacobin, intervino-, lo que le convenció y le preparó para lanzar textos más directos y accesibles, como su libro póstumo.

\section{UTOPIAS REALES Y CIENCIA SOCIAL EMANCIPATORIA}

El recetario de utopías reales que fue elaborando incluía la democracia asociativa, la renta básica, el capital único (una dotación económica universal al cumplir la mayoría de edad), los presupuestos participativos, el uso del sorteo en diferentes fases del proceso político, las cooperativas de trabajadores, la producción colaborativa de redes de pares (como la Wikipedia o el software libre), la economía social y solidaria, la transparencia informativa de los gobiernos, la financiación igualitaria de las campañas electorales, el apoyo mutuo comunitario, las políticas de igualdad de género en la familia y el trabajo, la propiedad intelectual de acceso abierto, los laboratorios tecnológicos comunitarios (o fablabs), las cooperativas de consumidores y de cadenas de distribución, y un largo etcétera.

Como recordaba Burawoy (2019): “Erik exploró el planeta en busca de utopías reales en ciernes, poniendo cada una de ellas bajo su microscopio analítico y elaborando diseños más generales sobre esa base" (p. 830). Los ejemplares que fue recolectando por el camino eran ciertamente desiguales: desde la ambiciosa propuesta, puramente teórica, de un socialismo de mercado basado en la distribución igualitaria de cupones, hasta experiencias reales, pero bastante modestas, de participación de las familias y comunidades en la vida de los centros educativos ${ }^{7}$. Pero lo interesante era muchas veces el microscopio analítico para pensar cómo podían desarrollarse, replicarse o escalarse los principios institucionales de cada propuesta. Es improbable que Wikipedia fuera a terminar con la explotación capitalista, pero mostraba que en nuestra sociedad ya existen prácticas

6 Si bien Wright siempre se caracterizó por su enorme claridad expositiva, es probable que su exceso de celo analítico a la hora de precisar los conceptos, desarrollar los argumentos y anticiparse a posibles objeciones fuera en detrimento de un estilo más directo o afilado con el que llegar a un público más amplio. Por otro lado, sospecho que su rechazo a la escritura críptica o grandilocuente le privó de una posición más destacada en el parnaso de los intelectuales críticos. John Searle (2004) recuerda cuando Foucault y luego Bourdieu -autores a los que apreciaba y cuyas ideas influyeron en su obra- le explicaron que si en Paris el diez por ciento de lo que escribes no era incomprensible, parecías poco profundo y nadie te tomaba en serio. El estilo de Wright representaba el extremo opuesto a este mecanismo de distinción.

7 Marion Fourcade-Gourinchas (2012) ha señalado críticamente que la desatención a esferas tan relevantes como la organización macroeconómica o la regulación financiera obedece a que su naturaleza enormemente técnica dificulta una intervención democratizadora. Wright (2012) admite esa dificultad, pero niega que resulte, en principio, imposible. En el extremo opuesto, otros autores (Ahlberg y Brighouse, 2014) han reconocido que para la reforma de algunas instituciones -como el sistema educativopuede ser más productivo pensar en términos de bettertopians: propuestas de mejora más modestas que las real utopias. 
que responden a lógicas -en este caso, "de cada cual según su capacidad, a cada cual según su necesidad"- alternativas a las del capitalismo.

El análisis de esas propuestas para el rediseño institucional giraba en torno a tres tipos de cuestiones que, aunque podían solaparse, convenía diferenciar: su deseabilidad normativa, su viabilidad técnica y su factibilidad política. El debate sobre su deseabilidad normativa contribuía a clarificar los valores que estaban en juego, si las propuestas ayudaban a realizarlos y los potenciales dilemas entre ellos. El debate en torno a su viabilidad se proponía examinar las dificultades y controversias técnicas que había de afrontar cada propuesta, así como anticipar su sostenibilidad en el tiempo. El debate en torno a su factibilidad se centraba en las estrategias y equilibrios políticos que podían favorecer u obstaculizar su desarrollo. No todas las alternativas deseables tenían por qué ser viables; ni todas las técnicamente viables, políticamente factibles.

Si bien la cuestión acerca de la deseabilidad normativa no concernía tanto a la ciencia social, como al propio debate público (que la filosofía política podían ayudar a clarificar), los aspectos relativos a la factibilidad técnica y la viabilidad política invitaban al uso práctico de la ciencia social para analizar diferentes problemas: el funcionamiento en el mundo real de los principios institucionales, los efectos de diferentes contextos, las potenciales sinergias con otras instituciones, su dinámica a lo largo del tiempo (que incluía eventuales contradicciones y formas de contrapesarlas), o la posibilidad de extenderlas y desarrollarlas en otros ámbitos, así como el tipo de fuerzas sociales que podían apoyarlas u combatirlas, las oportunidades y los obstáculos con los que podían tropezar y el modo en que las dinámicas de cambio social contribuían a modificar unas y otros. Todas esas cuestiones relativas al diseño y el cambio institucionales podían ser respondidas con ayuda de la ciencia social, por más que para algunas se dispusiera de una evidencia más sólida y para otras hubiera grandes zonas de incertidumbre, en las que sólo cabía una prudente especulación.

En ese sentido, uno de los aspectos clave del análisis de estas propuestas era contemplar de forma realista los dilemas prácticos de cada propuesta y sus posibles consecuencias perversas inintencionadas. Consciente del resultado de algunas experiencias pasadas, Wright admitía que "el camino al infierno está empedrado de buenas intenciones" y que había que tener en cuenta la crítica a la "fatal arrogancia" (Hayek, 1990) de quienes se adentraban en la ingeniería social (ver también Fernández Buey, 2007). Pero considerar los peligros de esa empresa no implicaba que fueran su inevitable destino. Que las retóricas de la reacción con las que suele responderse a los proyectos emancipadores de cambio social pueden tener un punto de verdad no quiere decir que sean siempre verdaderas, pero sí invita a ser más cautelosos de lo que se ha sido a veces con sus posibles consecuencias inintencionadas.

Analizar concienzudamente estas utopías reales no sólo tenía un interés práctico inmediato, pues la viabilidad política de alguna de ellas se antojaba lejana, sino que era relevante también por sus efectos performativos a medio plazo. La discusión de alternativas realizables, basadas en prácticas prefigurativas ya existentes, era la mejor forma de ampliar la imaginación política y cuestionar lo que Mark Fisher (2018) denominó el "realismo capitalista": "La idea de que el capitalismo no sólo es el único sistema político viable, sino que es imposible incluso imaginarle una alternativa" pues "ocupa sin fisuras el horizonte de lo pensable" (pp. 22 y 30). Puesto que "los límites de posibilidad [del cambio social] no son independientes de las creencias acerca de dichos límites" (Wright, 2014, p. 39), explorar la viabilidad de las utopías reales era una forma de ensanchar tales límites. Como veremos, esa ampliación de la imaginación política iba de la mano de una apuesta por el pluralismo institucional y estratégico. 
La reflexión sistemática sobre las utopías reales era, en todo caso, solo una de las tres tareas de lo que denominó "ciencia social emancipadora" - "la generación de conocimiento científico-social relevante para el proyecto colectivo de suprimir las múltiples formas de opresión humana" (Wright, 2014, p. 27)-, que incluía otras dos más: el diagnóstico y la crítica sistemáticos de la realidad social, y el análisis del obstáculos, posibilidades y dilemas para su transformación. Por usar su propia metáfora: "Podemos pensar en la ciencia social emancipadora como la crónica de un viaje desde el presente hasta un futuro posible: la crítica de la sociedad nos dice por qué queremos dejar el mundo en el que vivimos; la teoría de las alternativas nos dice a dónde queremos ir; y la teoría de la transformación nos dice cómo llegar desde aquí hasta allí" (Wright, 2006, p. 99).

La razón para llamar científico a este tipo de conocimiento era que no se trataba simplemente de la crítica o filosofía social, sino del análisis sistemático de los mecanismos causales con los que funciona el mundo social La razón para llamarlo emancipador era reconocer que había un propósito moral en la producción de este conocimiento. Desde esta perspectiva, puede decirse que no había nada exactamente nuevo, ni Wright lo pretendía, en una idea que no hacía sino reflejar la práctica de muchos investigadores sociales $^{8}$. En realidad, la poca atención que dedicó a fundamentar esta idea hace pensar que lo que más le interesaba era señalar las tareas y no la naturaleza (o la demarcación) de la ciencia social emancipadora9 .

Dicho esto, la idea de ciencia social emancipadora no sólo invitaba a reflexionar con más claridad acerca de esas tareas -es decir, de los asuntos que podían conformar su agenda investigadora- sino que permitía detectar los posibles desequilibrios entre ellos (por ejemplo, la frecuente desatención a las alternativas y las estrategias para su aplicación en comparación con el diagnóstico crítico de los problemas sociales) y facilitaba el diálogo entre líneas investigadoras que, debido a la especialización y fragmentación académicas, pueden permanecer desconectadas.

Con todo, es posible que la etiqueta de "emancipadora" pueda despertar el recelo de algunos defensores de la "neutralidad axiológica" que temen que la intromisión de los valores ponga en peligro la integridad o la calidad de la investigación científica. Pero creo que ese temor es un tanto injustificado. El énfasis en la dimensión emancipadora de la ciencia social no está reñido con su carácter explicativo ni con el compromiso con las reglas metodológicas convencionales. Es decir, es posible y deseable formular teorías que contribuyan a "liberar a los seres humanos de las circunstancias que los esclavizan" -por usar la expresión de Max Horkheimer (1972, p. 244)- con ayuda de las prácticas convencionales de la ciencia social.

El carácter emancipador de esta tarea no responde a un "método" o un "paradigma" distintos, sino más bien a la elección de los problemas que se propone resolver y, en cierto modo, a la forma que tiene de conceptualizarlos. En ese sentido, la idea de ciencia social emancipadora quizás pueda propiciar una relación más productiva entre ciencia y política por dos vías complementarias: persuadiendo a activistas (e intelectuales críticos) de las posibilidades que ofrece el conocimiento científico-social e invitando a los investigadores comprometidos a una reflexión sobre la relevancia o las prioridades de su campo de investigación.

En cuanto a los valores, el propio Weber (2017) admitía que desempeñan un papel clave a la hora de escoger un tema de estudio y elaborar los conceptos para abordarlo, y lo

8 De hecho, en la propuesta de Wright puede apreciarse un aire de familia con algunas ideas de Habermas (1992), un aspecto sobre el que, debido a la falta de espacio, no es posible profundizar aquí.

9 La mejor prueba de ello es la ausencia de una discusión metodológico-filosófica similar a la que incluían obras como Clases y el hecho de ni siquiera mencionara la idea en las 24 páginas del programa de su curso de doctorado sobre filosofía de las ciencias sociales, que se encuentra disponible, como todos sus textos, en su pagina web. 
cierto es que su influencia también se deja notar en el modo de lidiar con la incertidumbre epistémica, las decisiones sobre qué aspectos de un problema son más importantes y cuál es la mejor forma de abordarlos o la forma de enmarcar discursivamente la información científica (Elliott, 2017). En realidad, los valores son una parte esencial del razonamiento científico, que aparece incluso en la estructura lógica de una explicación ${ }^{10}$, e ignorar esto solo lleva a que esa influencia sobreviva sin estar sujeta al escrutinio adecuado. Como concluye Kevin Elliot (2017): "Pretender excluir a los valores es un poco como afirmar que no deberían permitirse los cuchillos en las cocinas porque la gente se puede hacer daño con ellos" (p. 8).

El propio Elliot (2017) establece tres criterios -que Wright cumple a la perfección- para vigilar que su influencia no sea perniciosa: que sea lo más transparente posible, que sea representativa de prioridades ético-sociales ampliamente compartidas, y que pueda examinarse a través de un proceso de diálogo entre científicos y otras partes interesadas. Si bien el segundo es controvertido -sería imposible convencer de los criterios normativos que utiliza Wright a un seguidor de Ayn Rand que niegue todo sentido al propio concepto de "justicia social"-, se trata de un escollo inevitable -relacionado con la propia naturaleza polémica de las ciencias sociales- que admite soluciones pragmáticas. Dicho esto, Wright no pretendía involucrar a toda la sociología en la empresa de la ciencia social emancipadora, si bien las utopías reales y su idea de socialismo apelaban a un público muy amplio pues -como veremos a continuación- permitían conectar con intuiciones morales ampliamente compartidas.

\section{EL PLURALISMO INSTITUCIONAL DEL SOCIALISMO}

Para Wright el socialismo era una forma de organizar las instituciones sociales que buscaba satisfacer tres grupos de principios normativos: igualdad/justicia, democracia/ libertad y comunidad/solidaridad (Wright, 2019). Puesto que esos ideales también entroncan con la rama igualitarista de la tradición liberal y vienen a coincidir con la triada "libertad, igualdad, fraternidad", cabe preguntarse qué sentido tenía entonces seguir hablando de "socialismo"11, aunque solo fuera por una razón publicitaria. Como cuenta el propio Wright que le regañaba su madre: "marxismo y socialismo no hacen más que espantar a la gente; no uses esas palabras" (Wright, 2018); a lo que respondía que se sentía en la obligación de disputar los significados ligados a ellas. Creo que lo que subyacía a esta decisión eran la honestidad intelectual y la firmeza moral que le caracterizaron: lo correcto era enseñar sus cartas, aunque fueran a contracorriente.

\footnotetext{
10 Como argumenta Alan Garfinkel (1981), puesto que las explicaciones causales son siempre incompletas, en el sentido de que no puede establecerse la causa de un fenómeno, sino que hay que distinguir algunos factores causales relevantes de las condiciones de fondo (o antecedentes), tanto la separación de éstas de aquéllos como la elección de un espacio de contraste del explanandum (la alternativa al fenómeno a explicar que se considera relevante) limitan el campo de lo que se presupone posible de un modo que está influido o sesgado por los valores, aún cuando no responda directamente a la motivación del investigador. El efecto práctico es que un marco explicativo tiende a predeterminar el rango de fines posibles para los que puede aconsejar qué medios son más óptimos. Por no hablar de que, en el mundo real, el debate científico sobre qué medios son mejores para lograr ciertos fines con mucha frecuencia no puede escapar a una ponderación implícita y cargada de valores sobre el peso de los diferentes fines que se considera valioso perseguir (Hausman, McPherson y Satz, 2017).

11 Esta visión ecuménica recuerda a la siguiente anécdota relatada por Barbara Nestor: “Cuando mi padre se enteró de que había asistido a una reunión socialista con 16 años y medio, me reprendió: "¿qué hacías tú en un mitin socialista?" Yo le respondí: “Papá, ¿qué sabes realmente del socialismo?" Me dijo: "Bien, dicen que el socialismo no cree en Dios, ni en el matrimonio o algo así". Yo le dije, "mira, papá, el socialismo no tiene nada que ver con Dios ni con algo así. El socialismo es la creencia de que todo el mundo debe tener la oportunidad de desarrollarse, de que todo el mundo es tan bueno como cualquier otro. Nadie es mejor, no importa lo alto o bajos que sean. Son todos seres humanos..." Él me dijo: "pero entonces eso es lo que Dios quiere". Yo respondi: "Entonces los socialistas están intentando hacer lo que Dios quiere porque eso es el socialismo" (citado en Healey e Isserman, 1993, p. 21). Barbara Nestor era la madre de la dirigente comunista norteamericana Dorothy Healey, conocida como la Red Queen de Los Ángeles, cuyo nieto, Josh Healey - por el cual conozco esta anécdota - fue estudiante de Erik Wright, quien escribió unas palabras para uno de sus poemarios.
} 
En el corazón de este ideal democrático-igualitario está la idea de que las instituciones sociales deben establecer las condiciones (y reducir los obstáculos) para el florecimiento humano, consistente en que cada persona pueda desarrollar sus capacidades del modo que crea oportuno. Por decirlo de algún modo, el espíritu utópico no respondía a la idea de una sociedad perfecta, sino al horizonte de una vidas más prósperas. Eso implicaba un acceso equitativo a los medios materiales y sociales necesarios para el florecimiento personal y para la participación en la adopción de decisiones acerca de los asuntos colectivos (es decir, una mayor justicia social y política, respectivamente). Para ello era necesaria una expansión y profundización de la democracia en las instituciones sociales, algo que él concebía como un "incremento del poder social" [social empowerment] (o del poder de la sociedad civil) en la forma de organizar la asignación, el control y la utilización de los recursos económicos.

Wright distingue tres tipos fundamentales de estructuras económicas -capitalismo, estatismo y socialismo- definidas por el tipo de poder en que se basan: respectivamente, el poder económico (la propiedad y control de los recursos económicos), el poder estatal (el control de la elaboración, promulgación y control del cumplimiento de normas), y el poder social (la capacidad de movilizar a la gente a favor de acciones colectivas voluntarias de distinto tipo). En claro contraste con la identificación heredada del socialismo como un sistema dominado por el Estado, Wright rechaza la oposición dicotómica entre capitalismo y estatismo y defiende rescatar "lo social" del socialismo: es decir, el principio básico era la expansión y profundización de la democracia, entendida como la preponderancia del poder de la sociedad civil sobre los poderes económico y del Estado.

Este marco incluía dos ideas clave. Las primera era que en la realidad histórica los tres tipos de estructuras económicas no se presentan en solitario y de forma pura, sino articuladas como híbridos estructurales que combinan elementos o principios institucionales de todos ellos. Es decir, incluso en una sociedad capitalista podemos distinguir la presencia de estructuras estatistas o socialistas ( $\mathrm{y}$, consecuentemente, un grado variable de su "capitalisticidad"). Lo relevante es cuál de ellas tiene preponderancia (asunto difícil de resolver con precisión, como admitía Wright), pero que sirve como faro heurístico. La segunda era que estos híbridos económicos pueden articularse por medio de diversos arreglos institucionales más complejos y plurales de lo que el debate político contemporáneo tiende a admitir. Esto abría la puerta a un desarrollo de la imaginación institucional para proponer combinaciones alternativas tomando pie en la propia complejidad y variabilidad institucional del híbrido capitalista existente.

Wright llama a estas combinaciones "vías para el incremento del poder social" y distingue siete de ellas (recogidas, junto a otra "estatista", en el gráfico 1), ilustrándolas con diferentes ejemplos empíricos: el socialismo estatista; la regulación estatal y la democracia asociativa propias de la socialdemocracia; la economía social pura o por medio del capitalismo social; la economía cooperativa de mercado, y el socialismo participativo. Todos ellos se distinguen del contraejemplo del estatismo autoritario (recogido en la parte inferior derecha del gráfico) -donde el poder del Estado prevalece en la vida económica y sobre la propia sociedad civil- en que devinieron muchas de las experiencias del siglo XX. Esta diversificación de las alternativas institucionales y sus posibles combinaciones venía a sustituir a la confianza exclusiva en el papel del Estado como palanca para contener al, y superar el, capitalismo. En lugar del mapa que ofrecía la visión tradicional del marxismo, disponíamos de una brújula que indicaba si nos movíamos en la dirección de un mayor protagonismo del poder -directo o indirecto- de la sociedad civil sobre la vida económica y política. 
Gráfico 1. Vías para el incremento del poder social
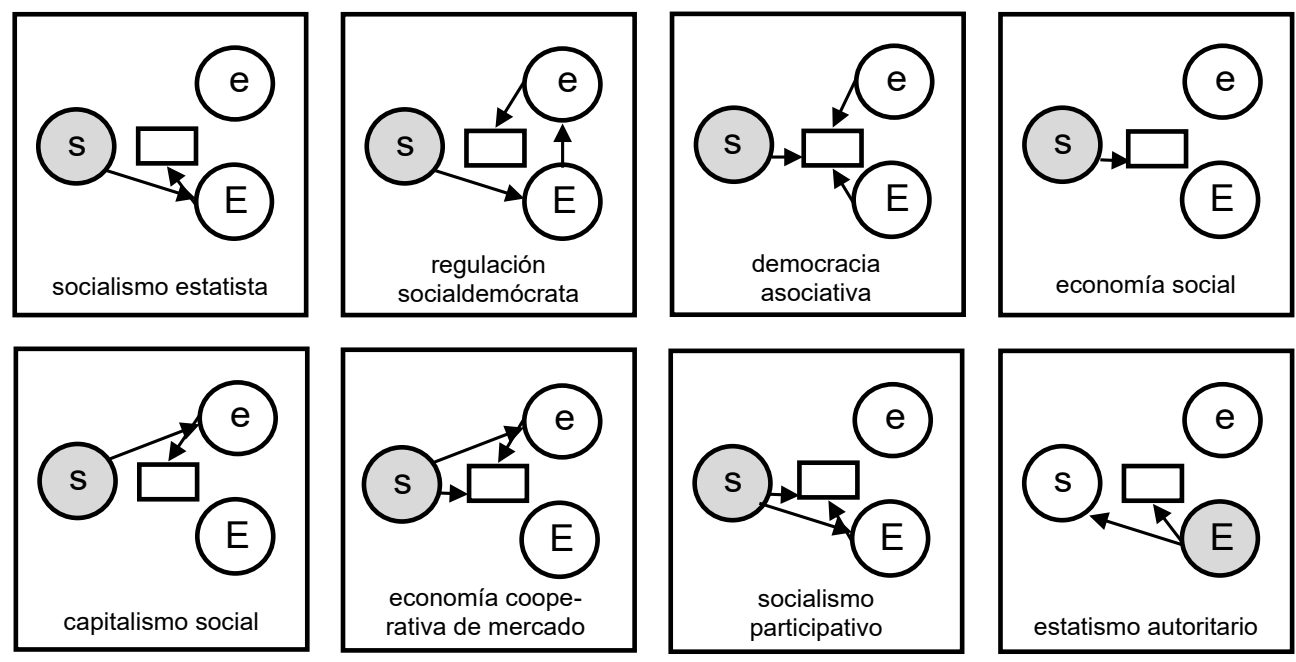

Fuente y notas: Wright (2014). Los tres círculos representan los tres tipos de poder: $\mathrm{s}=$ poder social; $\mathrm{e}$ = poder económico y $\mathrm{E}$ = poder del Estado y el rectángulo, la economía (entendida como la asignación de recursos y control de la producción y distribución). Las flechas representan la dirección de la influencia y el gris el tipo de poder que es preponderante.

A este pluralismo institucional subyacía la idea de que es más apropiado pensar las sociedades o las economías como ecosistemas antes que como organismos: no son sistemas perfectamente integrados y coherentes, sino que comprenden elementos contradictorios en equilibrios cambiantes. Unido a esto, había que prestar una mayor atención al nivel institucional para captar los elementos o principios que coexistían, de formas variables, en las estructuras económicas existentes (en línea con los análisis comparativos del capitalismo y sin por ello olvidar el nivel estructural que tradicionalmente había acaparado la atención del marxismo). El hecho de que los híbridos estructurales contuviesen principios institucionales discrepantes, variables y combinables ofrecía más posibilidades para su transformación de lo que tradicionalmente se había supuesto. Por decirlo de otro modo, ya existían elementos "socialistas" que se podían potenciar aprovechando las brechas, contradicciones y limitaciones del híbrido (o los híbridos) capitalistas existentes. Obviamente, esta ampliación de las posibilidades no era ilimitada: una cosa es que las estructuras no sean organismos perfectamente integrados, y otra que cualquier combinación ecológica sea posible, pero muchas veces no sabemos con certeza cuáles lo son y cuáles, no.

Hay otros dos aspectos de la visión del híbrido socialista de Wright que contrastan con el tronco principal de la tradición marxista durante el siglo XX. El primero era que dejaba amplio espacio para el mercado. En este punto, Wright no solo admitía muchas ventajas relativa de este mecanismo de coordinación económica y otros tantos inconvenientes de la alternativa de la planificación estatal (en especial, a la luz del experimento soviético), sino que mostraba una actitud flexible y agnóstica ante los diferentes mecanismos institucionales que pueden servir para realizar los ideales democráticos e igualitarios. Esta actitud, que conectaba con una rama olvidada de la tradición socialista, era un acicate para la imaginación institucional y permitía tender puentes con otras perspectivas ideológicas. 
El segundo aspecto es el papel secundario que ocupa la clase. La clase trabajadora seguía desempeñando un papel relevante en el diagnóstico crítico de la realidad y en el diseño de muchas utopías reales (como ocurría con los sindicatos en el caso de la democracia asociativa o con las cooperativas de trabajadores), pero había sido desplazada del centro de la escena por la "sociedad civil". Algunos tildaron este desplazamiento de "neoliberalización del socialismo" o "marxismo neotocquevilliano" (Fourcade-Gourinchas, 2012; Riley, 2012). Es cierto que el concepto de sociedad civil podía resultar analíticamente impreciso y políticamente ambivalente, pero Wright no perdía de vista su potencial lado oscuro $^{12}$ : la sociedad civil podía adoptar formas abiertamente contrarias a las utopías reales que defendía, por lo que era menester considerar y conjurar ese peligro.

Pero apelar a ella y tomarla como base permitía integrar mejor todas las propuestas utópico-realistas y ampliar los actores sociales a los que se podía apelar para luchar por ellas, por más que no quedaran del todo claras las divisiones -de clase, género, etnia u otras-, y los consiguientes conflictos potenciales, que podían darse entre ellos. En el fondo de este desplazamiento también puede adivinarse una conclusión a la que había llegado su programa de análisis de clase: "la clase ya no era una fuerza transformadora" (Burawoy, 2020, p. 81), al menos en el sentido que le había encomendado la tradición marxista. Las consecuencias más serias de este cambio aparecían en el plano estratégico.

\section{LÓGICAS ESTRATÉGICAS: ADIÓS A LA REVOLUCIÓN}

Junto al pluralismo institucional, Wright (2014) defendió un pluralismo estratégico para llevar a cabo las utopías reales que defendía. Inicialmente, distinguió tres tipos de estrategias de transformación social: la rupturista, basada en una brusca discontinuidad con las estructuras existentes por medio de la confrontación directa y el cambio repentino; la intersticial, basada en la construcción gradual de nuevas formas de organización por la sociedad civil en los nichos y márgenes de la sociedad capitalista; y la simbiótica, basada en compromisos con el Estado y las élites que, a cambio de resolver ciertos problemas inmediatos, permiten desplazar a largo plazo los equilibrios de poder en la sociedad.

En su libro póstumo, Wright (2019) amplía ese menú y distingue hasta cinco lógicas estratégicas en función del nivel en que operan y el objetivo al que responden (ver tabla 1): destruir el capitalismo (similar a la estrategia rupturista); desmantelarlo por medio de la acción del Estado para introducir otro tipo de estructuras; domesticarlo, neutralizando o amortiguando muchos de los daños que provoca en la vida de las personas; resistir al capitalismo, por medio de la protesta directa ante determinados problemas; y escapar a él, a través de la creación de formas alternativas en los intersticios de la sociedad capitalista.

Tabla 1. Tipología de estrategias anticapitalistas

\begin{tabular}{cccc}
\hline & & \multicolumn{2}{c}{ Objetivo de las luchas } \\
\cline { 3 - 4 } & & Neutralizar los daños & Transcender las estructuras \\
\cline { 3 - 4 } Nivel del & El juego & Destruir \\
sistema & Reglas del juego & Domesticar & Desmantelar \\
& Jugadas & Resistir & Escapar \\
\hline
\end{tabular}

Fuente: Wright (2019, p. 56)

12 Por citar un caso elocuente, el ascenso del nazismo parece haber sido mayor en los lugares donde el asociacionismo era más fuerte (Satyanath, Voigtländer y Voth, 2017). 
La idea clave era que no había que elegir una de ellas: "A menudo sucede que los activistas se comprometen profundamente con una u otra de estas visiones estratégicas, que les parece universalmente válida, y malgastan demasiadas energías en el rechazo de los demás modelos" (Wright, 2006, p. 107). Pero en realidad Wright desechaba la primera y proponía una "configuración estratégica", conformada por las otros cuatro (sombreadas en la tabla), a la que denominaba erosionar el capitalismo. Esta apuesta por el gradualismo confiaba en que el avance progresivo de los componentes socialistas en el ecosistema económico adquiriese la suficiente prominencia en la vida de individuos y comunidades para desplazar los componentes capitalistas (y estatistas).

Wright exponía abiertamente sus razones para rechazar la estrategia rupturista consistente en "destruir" el capitalismo: el horizonte revolucionario clásico no sólo era inviable en el presente, sino que ni siquiera parecía deseable, puesto que las dificultades económicas que afrontaría harían muy probable el recurso a métodos no democráticos que conducirán a algo parecido al autoritarismo estatista. Esta postura no fue bien recibida por algunos marxistas, a quienes disgustaba su "enervante orientación socialdemócrata, que le apartaba de cualquier compromiso real con la tradición socialista revolucionaria" (Riley, 2016).

La propuesta de Wright podía recordar a la denostada idea de Eduard Berstein según la cual el socialismo llegaría tan suavemente como el alba: a través de pequeñas reformas que van elevando el sol socialista sobre el horizonte (Medina Sierra, 2019, p. 109). Pero lo cierto es que esta visión gradualista casa mejor de lo que parece con la propia trayectoria histórica que condujo al capitalismo: este sistema no emergió de un día para otro, sino a través de un "proceso prolongado y sinuoso a lo largo de varios siglos" en el que "las agitaciones políticas e incluso las revoluciones más que constituir una ruptura con las estructuras económicas, sirvieron para ratificar y racionalizar cambios que ya habían tenido lugar" (Wright, 2019, p. 61) ${ }^{13}$.

Pero, por esa misma razón y atendiendo a la realidad histórica, quizás convenga matizar el rechazo de Wright a la estrategia rupturista-destructiva. Si pensamos en las opciones estratégicas como modelos, podemos concebir sus diferencias como un continuum. En ese sentido, hay propuestas "desmanteladoras" que se acercan, por la ambición de su alcance y el conflicto que implican, al polo rupturista. Un ejemplo es el famoso Plan Meidner de "fondos de asalariados" defendido por los sindicatos suecos en los años setenta ${ }^{14}$. Se preveía que las empresas pagaran un impuesto sobre sus beneficios emitiendo nuevas acciones que se depositaban en una red de fondos de inversión controlados por los asalariados. Con el paso del tiempo, se produciría una redistribución gradual de la propiedad del capital, respetando los incentivos de mercado y la capitalización de las empresas: es decir, las acciones seguían en ellas, aunque sus propietarios fueran distintos. El plan se proponía arrebatar el poder sistémico de los capitalistas asociado a su control sobre la inversión, y sus efectos podían ser profundos: si las empresas emitían un $20 \%$ de sus beneficios anuales en nuevas acciones, se calculaba que en tres décadas la mitad de la economía sueca estaría en manos de esta red de fondos.

De este caso y, más en general, del conjunto de estrategias -desmanteladoras y domesticadoras- de la socialdemocracia de la segunda mitad del siglo XX se pueden extraer dos claves. Por un lado, el papel que desempeñó el sueño y la amenaza revolucionarias

\footnotetext{
13 En este sentido, la crítica de Riley es representativa del modo en que la imaginación política se ha visto apresada por esquemas estériles -como el de "reforma o revolución"-que, si bien respondían a dilemas reales en el contexto histórico en el que nacieron, carecen de sentido en otros distintos como el nuestro. Eso ya empezaba a resultar evidente hace casi un siglo para figuras -como Bauer o Gramsci- cuyos planteamientos, o lo que se desprende de ellos, entroncan con la postura de Wright (Sassoon, 2001, cap. 3)-, lo que no ha impedido que los efectos perniciosos de tales esquemas perduraran durante mucho tiempo. 
para favorecer la viabilidad de los proyectos igualitaristas en Europa occidental durante ese periodo. En ese sentido, surgen las preguntas de hasta qué punto su ausencia puede convertirse en un obstáculo para la viabilidad de la erosión gradualista del capitalismo, y qué otro tipo de visión - ¿una en torno a la democracia?- podría servir como un mito movilizador a su favor.

Por otro lado, estas estrategias socialdemócratas se apoyaron en la fuerza del movimiento obrero organizado. Su desplazamiento, en el proyecto de Wright, del centro de la escena en favor de una sociedad civil amplia y plural, pero también más fragmentada, plantea serios problemas. Ciertamente, hay buenas razones para no fiarlo todo a una fuerza social en declive y cuya centralidad política durante el pasado siglo quizás sea una excepción histórica irrepetible. Las apelaciones al "99\%" durante el ciclo de protesta reciente no deben ocultar el creciente protagonismo de las clases medias (en particular, de los profesionales socioculturales) tanto en las movilizaciones sociales (Hylmö y Wennerhag, 2015; Tugal, 2015) como en el apoyo electoral a los partidos de izquierda (Gingrich y Häusermann, 2015; Oesch, 2012). Con todo, no está claro que una miríada de actores de la sociedad civil pueda lanzar una ofensiva al enorme poder del $1 \%$ sin la presencia de un actor fuertemente organizado y ligado a las clases populares como lo fue el movimiento obrero (Chibber, 2020).

¿Cómo podría ayudarnos la ciencia social emancipadora a resolver estos dilemas estratégicos? Wright explora lo que llama "elementos de una teoría de las estrategias transformadoras" en un plano básicamente conceptual y programático, distinguiendo los mecanismos que aseguran la reproducción social, los que provocan fallos y contradicciones en ella y los que subyacen a las trayectorias de cambio social inintencionado. El tono abstracto de esta parte de su trabajo eludía las cuestiones prácticas más acuciantes que debía afrontar la lucha política: por ejemplo, es llamativa la omisión de referencias a los partidos políticos.

En su libro póstumo abordó con algo más de detalle dos de los problemas centrales sobre los que gravitaban las cuestiones estratégicas de tipo práctico: el papel del Estado y la formación de los actores colectivos. En cuanto a la primera, retoma las conclusiones de una agenda investigadora interrumpida a mediados de los años ochenta (impulsada por autores como Fred Block, Claus Offe y Göran Therborn) para evaluar las limitaciones y posibilidades de transformación que presentaba el Estado bajo el capitalismo. Junto a las dificultades que podían anticiparse -la dependencia "estructural" del Estado respecto al capital, el sesgo de clase en el reclutamiento de los altos funcionarios o las restricciones que introducian las inercias institucionales-, Wright señalaba dos circunstancias que invitaban al optimismo: la emergencia climática y los efectos de la automatización del empleo abrían la puerta a una mayor intervención del Estado, que podía orientarse en una dirección democratizadora (es decir, incrementando el poder social).

La segunda cuestión quizás sea más interesante por la conexión con su obra anterior. En el último capítulo de su libro póstumo, Wright (2019) se pregunta: “¿cómo crear actores colectivos con la suficiente coherencia y capacidad de lucha para sostener un proyecto que desafíe al capitalismo?" (p. 121), en un contexto de fragmentación de la estructura de clase y disputa entre diferentes fuentes de identidad. Al intentar clarificar esta cuestión, se asoma a un territorio que había estado ausente de su programa de análisis de clase: la formación de los actores colectivos más allá de las "clases sobre el papel" -por utilizar una expresión, injustamente peyorativa, de Bourdieu (1985)- que habían acaparado su atención. En este punto, Wright se aparta de la visión marxista centrada en los intereses ${ }^{15}$

\footnotetext{
15 Es tentador atribuir esa visión al marxismo "tradicional", pero probablemente está más presente en la teoría de la elección racional con la que algunos marxistas analíticos intentaron renovar el marxismo que -por poner un ejemplo-en las aportaciones de historiadores como E.P. Thompson, al que paradójicamente Wright no prestó mucha atención.
} 
e incluye las identidades y los valores como elementos clave de ese proceso. Es decir, el proyecto socialista no debía apelar únicamente a los intereses materiales, sino también a ciertos valores, como los señalados más arriba, en los que la gente se viera reflejada con cierta independencia de su posición social y sus identidades. La dificultad residía, claro está, en averiguar de qué modo valores como la comunidad o la solidaridad podían abrirse paso en un entorno dominado por otros valores, como "el individualismo competitivo y el consumo privatizado" (Wright, 2019, p. 32).

Al adentrarse en el territorio estratégico se hacían más patentes las limitaciones de nuestro conocimiento científico del mundo social. Por decirlo de algún modo, el proceso de formación de actores colectivos o el éxito de diferente estrategias responde en mucha mayor medida a la contingencia histórica que el diseño de utopías reales (o la cartografía de la estructura de clase, por señalar los dos asuntos en los que se había centrado Wright).

En un sentido más general, Wright era bien consciente de la opacidad e incertidumbre del mundo social y de los límites de la ayuda que podía brindar la ciencia social. Aunque no se extendió en este punto, podría decirse que abrazaba un racionalismo bien temperado - por usar la expresión de Fernández Buey (2004)- que, si bien no abandonaba el énfasis en el conocimiento científico del mundo social, admitía que la luz que éste puede arrojar llega hasta cierto punto, a partir del cual hay que caminar a tientas, echando mano del saber prudencial.

\section{A MODO DE CONCLUSIÓN}

Harry Brighouse (2019) recordaba el consejo que ofreció Wright a un estudiante aquejado por el bloqueo del escritor: la publicación de un trabajo académico debe verse como una contribución a una conversación en marcha antes que como una forma de zanjar un problema en la que todo debe quedar perfectamente cerrado; su objetivo es invitar al lector a pensar en el próximo paso. Esta idea ilustra bien el quehacer intelectual del propio Wright y el potencial que posee su trabajo sobre las utopias reales para la investigación social y la acción política.

Una de las lecciones que brinda a la reflexión crítica es que el movimiento se demuestra andando: la mejor forma de oponerse a las formas de opresión es formular alternativas concretas para eliminarlas o mitigarlas, propuestas realizables que convenzan a la gente de que el reino de los proyectos emancipadores es de este mundo. Pero para que ese movimiento llegue a buen puerto es necesario evitar, en la medida de lo posible, las trampas del autoengaño. Uno de los méritos de Wright fue no esconderse tras la retórica radical ante los dilemas y dificultades que la realidad histórica planteaba al proyecto socialista. Dicho de otro modo, estaba dispuesto a coger ese toro por los cuernos aunque eso le hiciera parecer un "enervante socialdemócrata" sin "compromiso con la tradición revolucionaria".

Por supuesto, las respuestas que ofreció Wright a esos dilemas y dificultades son discutibles, pero una de sus contribuciones decisivas fue precisamente aclarar los términos de esa discusión. Algo similar sucedía con su trabajo anterior, donde era posible disentir de su conceptualización de las clases medias o de su estrategia cuantitativa centrada en la estructura de clases, pero resultaba innegable que su labor de clarificación teóricoconceptual ofrecía un punto de partida inmejorable para continuar los debates de un modo productivo, evitando discusiones estériles. De igual modo, es posible discrepar del papel que concede a la sociedad civil en su visión del híbrido socialista o de su apuesta por una estrategia gradualista que erosione del capitalismo, pero su teorización ha allanado 
el terreno para desarrollar una discusión más provechosa, que no rehúya con grandes palabras las dificultades y dilemas a los que me refería antes ${ }^{16}$.

En un sentido sustantivo, la seña de identidad del programa de investigación de Wright fue la revitalización de la imaginación política por medio de un saludable pluralismo institucional y estratégico. En el plano institucional, la idea de que las estructuras económicas son siempre híbridas nos invitaba a pensar las múltiples combinaciones de Estado, mercado, asociaciones y comunidad que ya aparecen en la realidad y en las que debería basarse cualquier alternativa socialista. En el plano estratégico, el reconocimiento de los diferentes caminos invitaba a no malgastar energías en falsos dilemas y a mirar sin anteojeras las ventajas e inconvenientes de cada uno de ellos. En ambos casos, se trataba de liberar a la imaginación utópica de los marcos mentales en los que había quedado confinada.

Pero el socialismo utópico de Wright estaba anclado en el análisis científico-social de la realidad. El estudio sistemático de los procesos y mecanismos con los que funciona el mundo no sólo era una herramienta para el diagnóstico crítico de las formas de opresión, sino también para el diseño de utopías reales y la comprensión de las posibilidades y los obstáculos para su desarrollo. Su apuesta ilustrada por la ciencia social emancipadora venía acompañada, en todo caso, por un reconocimiento de la opacidad del mundo social y de los limites de nuestro conocimiento. Pese a todo su racionalismo, es posible que él mismo no escapara a veces al pensamiento desiderativo (véase, por ejemplo, la crítica de Panitch [2020] en relación a los presupuestos participativos), o que su "optimismo de la inteligencia" se acercara a veces al entusiasmo panglosiano. Como apuntaba Therborn (2020) en relación a su confianza en el gradualismo estratégico: "Wright era racionalista y pacifista; el mundo no es ninguna de las dos cosas" (p. 113). Pero también es posible que haga falta una dosis de entusiasmo infundado para pensar o hacer ciertas cosas.

Como decía al inicio, el programa de investigación de Wright en torno a las utopías reales también puede ser interesante para quienes sean renuentes a identificarse con sus objetivos políticos o a mezclarlos con su actividad académica. Su contribución a la teoría social puede resultar inspiradora para, entre otros campos, el análisis sociológicoeconómico de las variaciones y arreglos institucionales sin perder de vista el escenario estructural del híbrido capitalista, o el análisis sociológico-político del modo en que las estrategias y conflictos colectivos se entrecruzan con dinámicas estructurales de más largo alcance. Pero el énfasis de Wright en los ideales que se ven socavados por determinadas instituciones sociales o la búsqueda práctica de remedios para esas formas de opresión - que conecta de algún modo con el giro hacia la resolución de problemas sociales que han defendido otros sociólogos (Prasad, 2018; Watts, 2017)- también puede ser un acicate para reflexionar sobre los problemas que resulta más valioso estudiar y una invitación a utilizar la sociología para resolverlos.

Llegados a este punto, cabe preguntarse dónde queda la aspiración inicial de Wright de "reconstruir el marxismo", una vez que su propuesta adquiere un carácter intelectual y político más ecuménico, alejado de las "grandes batallas" teóricas con las que soñaba en su juventud -visible también en sus últimos trabajos sobre clase (Wright, 2005, 2015)-. Es muy probable que el último Wright, el renovador del socialismo utópico que en sus últimos días reflexionaba sobre la importancia del amor, la bondad y la generosidad, restara importancia a este asunto y suscribiera las palabras garabateadas hace tiempo por otro marxista atípico: "No se debe ser marxista (Marx); lo único que tiene interés es decidir si se mueve uno o no dentro de una tradición que intente avanzar por la cresta

\footnotetext{
16 En este sentido, Wright cumplió a rajatabla el memorable consejo de su madre que reproducía al inicio de Clases: "debes aprender a escribir de tal forma que a tus críticos les sea lo más fácil posible saber por qué están en desacuerdo contigo" (Wright, 1994: p. xi).
} 
entre el valle del deseo y el de la realidad, en busca de un mar en el que ambos confluyan" (Sacristán, 2003, p. 224).

\section{AGRADECIMIENTOS}

Una versión previa de este texto sirvió como base para mi intervención en las Jornadas en Homenaje a Erik Olin Wright celebradas en la Universidad Complutense de Madrid y la Universidad Nacional de Educación a Distancia los días 30 y 31 de enero de 2020, que fueron posibles gracias a la iniciativa de Julio Carabaña. Agradezco a todos los asistentes sus comentarios, especialmente a Diego Alonso, Miguel Caínzos, Inés Campillo, Julio Carabaña, Andrés de Francisco, Luís Fernando Medina, José Antonio Noguera y Natalia Pardo, así como a Julio Martínez-Cava, José Luís Moreno Pestaña, César Rendueles y Alberto Tena por las observaciones que me hicieron llegar por escrito. Todas esas críticas y sugerencias han servido para mejorar el texto, aunque sus posibles deficiencias siguen siendo responsabilidad mía.

\section{REFERENCIAS}

Ackerman, B. A., Alstott, A. y Parijs, P. van (2006). Redesigning distribution: Basic income and stakeholder grants as alternative cornerstones for a more egalitarian capitalism. Londres: Verso.

Ahlberg, J. y Brighouse, H. (2014). Education: Not a Real Utopian Design. Politics \& Society, 42(1), 51-72. https://doi.org/10.1177/0032329213512979

Blackburn, R. (2006). The Global Pension Crisis: From Gray Capitalism to Responsible Accumulation. Politics \& Society, 34(2), 135-186. https://doi.org/10.1177/0032329206288150

Bourdieu, P. (1985). The Social Space and the Genesis of Groups. Theory and Society, 14(6), 723-744. https://doi.org/10.1007/BF00174048

Bowles, S. y Gintis, H. (1998). Recasting egalitarianism: New rules for communities, states, and markets. Londres: Verso.

Brighouse, H. (2019). Erik Olin Wright 1947-2019 [en línea]. Recuperado de http://crookedtimber.org/2019/01/23/erik-olin-wright-1947-2019

Burawoy, M. (2019). Recordando a Erik Wright: Un utopista real en la teoría y la práctica. Sociología Histórica, (9), 822-833.

Burawoy, M. (2020). A Tale of Two Marxisms. New Left Review, (121), 66-98.

Chibber, V. (2020). How to Be a Socialist in the Twenty-First Century. Jacobin Magazine, (36), 53-59.

Cohen, G. A. (2001). Si eres igualitarista, ¿cómo es que eres tan rico? Barcelona: Paidós.

Cohen, J. y Rogers, J. (1995). Associations and democracy. Londres: Verso.

Elliott, K. C. (2017). A tapestry of values: An introduction to values in science. Nueva York: Oxford University Press.

Elster, J. (1991). Una introducción a Karl Marx. Madrid: Siglo XXI.

Engels, F. (1968). Del socialismo utópico al socialismo cientifico. San Sebastián: Equipo Editorial. 
Fernández Buey, F. (2004). La ilusión del método. Por un racionalismo bien temperado. Barcelona: El Viejo Topo.

Fernández Buey, F. (2007). Utopías e ilusiones naturales. Barcelona: El Viejo Topo.

Fisher, M. (2018). Realismo capitalista: ¿no hay alternativa? Buenos Aires: Caja Negra.

Fourcade-Gourinchas, M. (2012). The socialization of capitalism or the neoliberalization of socialism? Socio-Economic Review, 10(2), 369-375.

Garfinkel, A. (1981). Forms of explanation: rethinking the questions in social theory. New Haven: Yale University Press.

Gastil, J. y Wright, E. O. (2019). Legislature by Lot. Transformative Designs for Deliberative Governance. Londres: Verso.

Gingrich, J.y Häusermann, S. (2015). The decline of the working-class vote, the reconfiguration of the welfare support coalition and consequences for the welfare state. Journal of European Social Policy, 25(1), 50-75. https://doi.org/10.1177/0958928714556970

Gornick, J. C. y Meyers, M. (2009). Gender equality: Transforming family divisions of labor. Londres: Verso.

Habermas, J. (1992). Conocimiento e interés. Madrid: Taurus.

Harvey, D. (2005). Espacios de esperanza. Madrid: Akal.

Hausman, D. M., McPherson, M. S. y Satz, D. (2017). Economic analysis, moral philosophy, and public policy. Nueva York: Cambridge University Press.

Hayek, F. A. (1990). La fatal arrogancia: los errores del socialismo. Madrid: Unión Editorial.

Healey, D. e Isserman, M. (1993). California Red: A life in the American Communist Party. Urbana: University of Illinois Press.

Horkheimer, M. (1972). Critical theory. Selected essays. Nueva York: Herder and Herder.

Hylmö, A. y Wennerhag, M. (2015). Does class matter in anti-austerity protests? Social class, attitudes towards inequality, and political trust in European demonstrations in a time of economic crisis. En M. Giugni y M. T. Grasso (eds.), Austerity and protest: Popular contention in times of economic crisis (pp. 83-109). Londres: Routledge.

Jameson, F. (2007). Arqueologías del futuro. Madrid: Akal.

Jones, G. S. (1984). Reconsideración del socialismo utópico. En R. Samuel (ed.), Historia popular y política socialista (pp. 199-209). Barcelona: Crítica.

Marx, K. (1975). El capital. Libro primero. Madrid: Siglo XXI.

Medina Sierra, L. F. (2019). Socialismo, historia y utopía. Madrid: Akal.

Middleton, R. (2017). History of sociology at the University of Wisconsin-Madison. Madison: Anthropocene Press.

Mudge, S. L. (2018). Leftism reinvented: Western parties from socialism to neoliberalism. Cambridge: Harvard University Press.

Oesch, D. (2012). The Class Basis of the Cleavage between the New Left and the Radical Right: An analysis for Austria, Denmark, Norway and Switzerland. En J. Rydgren (ed.), Class Politics and the Radical Right (pp. 31-52). Londres: Routledge.

Panitch, L. (2020). Erik Olin Wright's Optimism of the Intellect. New Political Science, 42(1), 42-51. https://doi.org/10.1080/07393148.2020.1723962 
Prasad, M. (2018). Problem-Solving Sociology. Contemporary Sociology, 47(4), 393-398. https://doi.org/10.1177/0094306118779810

Riley, D. (2012). Neo-Tocquevillian Marxism: Erik Olin Wright's Real Utopias. Socio-Economic Review, 10(2), 375-381.

Riley, D. (2016). An Anticapitalism That Can Win. Jacobin. Recuperado de https://www. jacobinmag.com/2016/01/olin-wright-real-utopias-socialism-capitalism-gramsci-leninluxemburg/

Roemer, J. E. (1996). Equal shares: Making market socialism work. Londres: Verso.

Sacristán, M. (2003). M.A.R.X. Máximas, aforismos y reflexiones con algunas variables libres. Barcelona: El Viejo Topo.

Sassoon, D. (2001). Cien años de socialismo. Barcelona: Edhasa.

Satyanath, S., Voigtländer, N. y Voth, H.-J. (2017). Bowling for Fascism: Social Capital and the Rise of the Nazi Party. Journal of Political Economy, 125(2), 478-526. http://dx.doi.org/10.1086/690949

Searle, J. R. (2004). Lenguaje y ciencias sociales: Diálogo entre John Searle y Crea. Barcelona: El Roure.

Seidman, G. (2020). Class, gender and utopian community: In memory of Erik Olin Wright. Trabajo presentado en Transforming Capitalism Through Real Utopias: Featuring Erik Olin Wright's Legacy, Coimbra. Recuperado de https://thelifeandworkoferikolinwright.wordpress.com/conference-papers/

Therborn, G. (2007). Después de la dialéctica: La teoría social radical en un mundo poscomunista. New Left Review, (43), 59-106.

Therborn, G. (2020). An Agenda for Class Analysis. Catalyst: A Journal of Theory and Strategy, 3(3), 89-113.

Tugal, C. (2015). Elusive revolt: The contradictory rise of middle-class politics. Thesis Eleven, 130(1), 74-95. https://doi.org/10.1177/0725513615602183

Watts, D. J. (2017). Should social science be more solution-oriented? Nature Human Behaviour, 1(1), 0015. https://doi.org/10.1038/s41562-016-0015

Weber, M. (2017). La "objetividad" del conocimiento en la ciencia social y en la política social. Madrid: Alianza (original publicado en 1904).

Wright, E. O. (1983). Clase, crisis y Estado. Madrid: Siglo XXI.

Wright, E. O. (1993). Class Analysis, History and Emancipation. New Left Review, (I/202), 15-35.

Wright, E. O. (1994). Clases. Madrid: Siglo XXI.

Wright, E. O. (1995). Preface: The Real Utopias Project. En Cohen, J. y Rogers, J. Associations and democracy (pp. ix-xiv). Londres: Verso.

Wright, E. O. (1997). Class counts: Comparative studies in class analysis. Cambridge: Cambridge University Press.

Wright, E. O. (2005). Approaches to Class Analysis. Cambridge: Cambridge University Press.

Wright, E. O. (2006). Compass Points: Towards a socialist alternative. New Left Review, (41), 93-124. 
Wright, E. O. (2008). La clase sigue siendo uno de las divisiones centrales en las sociedades capitalistas contemporáneas. Entrevista [en línea]. SinPermiso. Recuperado de http:// www.sinpermiso.info/textos/la-clase-sigue-siendo-uno-de-las-divisiones-centralesen-las-sociedades-capitalistas-contemporneas

Wright, E. O. (2010). Envisioning Real Utopias. Londres: Verso.

Wright, E. O. (2012). Taking the social in socialism seriously. Socio-Economic Review, 10(2), 386-402.

Wright, E. O. (2014). Construyendo utopías reales. Madrid: Akal.

Wright, E. O. (2015). Understanding class. Londres: Verso.

Wright, E. O. (2018). Beatrice Ann Wright, December 16, 1917-July 31, 2018. Recuperado de https://www.caringbridge.org/visit/erikolinwright/journal

Wright, E. O. (2019). How to be an anticapitalist in the twenty-first century. Londres: Verso.

Wright, E. O., Levine, A. y Sober, E. (1992). Reconstructing Marxism: Essays on explanation and the theory of history. Londres: Verso.

\section{NOTA BIOGRÁFICA}

Jorge Sola es doctor en Sociología y Profesor Ayudante Doctor en el Departamento de Sociología: Metodología y Teoría de la Universidad Complutense de Madrid. Sus principales áreas de interés son la sociología política, la sociología económica y la teoría social, y su investigación ha girado en torno a la precarización del mercado laboral y la dimensión de clase de los procesos de cambio político. Ha publicado, junto a César Rendueles, el libro Le sfide di Podemos (Manifesto Libri, 2017). 